\title{
Anti-inflammatory activity of niosomes entrapped with Plai oil (Zingiber cassumunar Roxb.) by therapeutic ultrasound in a rat model
}

This article was published in the following Dove Press journal:

International Journal of Nanomedicine

29 March 2017

Number of times this article has been viewed

\author{
Jirakrit Leelarungrayub' \\ Jiradej Manorsoi ${ }^{2,3}$ \\ Aranya Manorsoi ${ }^{2,3}$ \\ 'Department of Physical Therapy, \\ Faculty of Associated Medical \\ Sciences, Chiang Mai University, \\ ${ }^{2}$ Manose Health and Beauty Research \\ Center, Mueng, ${ }^{3}$ Division of Cosmetic \\ Technology, Faculty of Science and \\ Technology, North Chiang Mai \\ University, Chiang Mai, Thailand
}

Correspondence: Jirakrit Leelarungrayub Department of Physical Therapy, Faculty of Associated Medical Sciences, Chiang Mai University, Intawaroroj Road, Sripoom, Chiang Mai 50200, Thailand Tel +66 53949272

Fax +6653946042

Email donrawee.leela@cmu.ac.th
Objective: The aim of this study was to evaluate the antioxidant and anti-inflammatory activities of Plai oil-encapsulated niosomes (Zingiber cassumunar Roxb.) on inflamed subcutaneous Wistar rat skin by therapeutic ultrasound.

Methods: Pure oil from Plai rhizomes was extracted by steam distillation, and antioxidant activities were determined by 2,2-diphenyl-1-picrylhydrazyl radical scavenging assay. Bioactive compounds were analyzed by gas chromatography-mass spectrometry. Niosome particles containing Plai oil were prepared by chloroform film method with sonication before testing for anti-inflammatory activity on locally inflamed subcutaneous rat skin after inducement from lipopolysaccharide with ultrasound once a day for 3 days. Skin temperatures and blood flow were evaluated.

Results: Plai oil presented antioxidant activity that inhibited 2,2-diphenyl-1-picrylhydrazyl radicals. Four active compounds found in the essential oil were sabinene, $\gamma$-terpinene, terpinene4-ol, and (E)-1-(3,4-dimethyoxy phenyl) butadiene. Application of ultrasound $\left(0.2 \mathrm{~W} / \mathrm{cm}^{2}, 20 \%\right.$, $3 \mathrm{~min}$ ) with gel containing Plai oil-encapsulated niosomes decreased skin temperature and blood flow to the lowest level compared to the application of neurofen drug or gel-based control.

Conclusion: Plai oil, which consists of four main bioactive compounds and possesses antioxidant and anti-inflammatory activities, can be applied against local subcutaneous inflammation when used with therapeutic ultrasound via entrapped niosomes.

Keywords: antioxidant, anti-inflammation, Plai oil, niosomes, therapeutic ultrasound, Zingiber cassumunar Roxb.

\section{Introduction}

Today, use of physical therapy to relieve pain or cure inflammation can be modified with various protocols such as rest and ice therapy before any therapeutic device application. Application of ultrasound is one of the many methods that has claimed to benefit the healing process and inflammation. ${ }^{1}$ Therapeutic ultrasound has been referred to as simple in the long term. ${ }^{2}$ The biological effects of ultrasound such as compressional, tensile, and shear stresses, including ultrasound energy transmission to improve blood circulation and biomolecule changes in inflammatory processes, are a part of basic knowledge. ${ }^{3}$ However, phonophoresis or sonophoresis is applicable sometimes when anti-inflammatory drugs, such as neurofen or lidocaine, are mixed with gel-based control during ultrasound application. In this case, application of ultrasound with anti-inflammatory drugs that eliminate pain or inflammation provides better clinical benefit than ultrasound alone. Nevertheless, ultrasound has been applied to eliminate pain or inflammation in clinics for a long time. On the other hand, many 
traditional plants have been used to release pain and inflammation, for example, Elaeodendron croceum and Calpurnia aurea extracts ${ }^{4}$ and Poikilacanthus glandulosus (Nees) Ariza leaves, ${ }^{5}$ including essential oil from Cameroon. ${ }^{6}$ Also, Thai medicinal plants such as Smilax corbularia Kunth, ${ }^{7}$ and Sahasthara, ${ }^{8}$ also present anti-inflammatory and antioxidant activities. Therefore, many medicinal plants present antiinflammation activity worldwide. Of many Thai medicinal plants, Plai (Zingiber cassumnar Roxb.) belongs to Zingiberaceae family and has specific characteristics such as yellow rhizome and slim leaf. Previous evidence confirmed that it possesses anti-inflammatory, ${ }^{9}$ anti-histamine, ${ }^{10}$ local anesthetic, ${ }^{11}$ and anti-pain ${ }^{12}$ activities. Each rhizome contains essential oil of $\sim 0.5 \%-0.9 \%$ of total fresh weight that is composed of Sabinene (25\%-45\%), $\gamma$-terpinene (5\%-10\%), alpha-terinene $(2 \%-5 \%)$, terpinene-4-ol $(25 \%-45 \%)$, and E-1-(3,4-dimethoxyphenl) butadiene (DMPBD) (1\%-10\%). ${ }^{13}$ Toxicity was not presented on rat or rabbit $\operatorname{skin}^{14-16}$ and neither was genetic mutation. ${ }^{9}$ A previous study showed that the skin absorbed essential oil $1 \mathrm{~h}$ after the oil was applied to the skin. ${ }^{17}$ Plai oil is currently a commercial product in Thailand as are many other products, for example, Plygesal ${ }^{\circledR}$ and Plaitanoids ${ }^{\mathrm{TM}}$ that are produced and distributed to relieve muscle pain. Unfortunately, after the oil has been extracted, its physical and chemical properties rapidly undergo changes, for example, a rancid smell and color change develop due to oxidation process when exposed to light or air, which relates to low stability and loss of active compounds. In 2005, a previous review proposed that microemulsion of essential oil had better benefits on skin application when used with ultrasound. ${ }^{18}$ Moreover, possibly clinical treated efficiency on sonophoresis has been proposed and suggested with modern transdermal delivery systems such as liposomes or niosomes. ${ }^{19}$ A previous report suggested that liposomes or niosomes, which were synthesized from Tween 80 by thin-film hydration technique, had more stability and high potential vehicles for delivering some compounds to tissues. ${ }^{20}$ Thus, the objective of this study was to develop a niosome prototype and modify Plai oil by encapsulating niosomes for application in therapeutic ultrasound in order to enhance the anti-inflammation activity of Plai oil.

\section{Materials and methods}

\section{Raw material and oil preparation}

Two-year-old rhizomes of Plai, without toxic insecticide spraying, were purchased from a local village farmer in Chiang Mai Province, Thailand. Plai rhizomes (Z. cassumnar Roxb.) were characterized by comparing them with a standard voucher specimen that was deposited at the Chiang
Mai University Biology Herbarium, Department of Biology, Faculty of Science, Chiang Mai University. Scraping the outermost shell of the fresh rhizome, cleaning, and slicing off pieces were performed before extracting the oil by steam distillation using Clevenger-type apparatus. Then, antioxidant activity and active compounds were analyzed.

\section{Antioxidant assay \\ I, I-Diphenyl-2-picryl hydrazyl (DPPH) radical scavenging}

The antioxidant activity of essential oil was analyzed by DPPH radical scavenging assay. ${ }^{21}$ After determining the density of Plai oil, the Plai oil diluted in ethanol $(50 \mu \mathrm{L})$ at $12.5-400 \mu \mathrm{g} / \mathrm{mL}$ was mixed in DPPH solutions and kept in dark for $30 \mathrm{~min}$. Absorbance was read by spectrophotometry at $515 \mathrm{~nm}$. The inhibition percentage of essential oil was compared with standard Trolox (Sigma, St Louis, MO, UK).

\section{Active compound analysis}

The major compound in Plai oil was identified by gas chromatography (CG)-mass spectrophotometry (MS) (Wiley7n.1) at the Science and Technology Service Center, Faculty of Science, Chiang Mai University, Thailand. The Agilent GC/ MS system consisted of GC6850 and a 5873 MSD, HP-MS 5 column $(30 \mathrm{~m} \times 0.25 \mathrm{~mm}$ ID $\times 0.25 \mu \mathrm{m}$ film thickness $)$. The flow rate of helium carrier gas was $1.0 \mathrm{~mL} / \mathrm{min}$ with the interface and ion source temperatures at $150^{\circ} \mathrm{C}$ and $230^{\circ} \mathrm{C}$, respectively. The program of $\mathrm{GC}$ analysis was set up with an inlet from $80^{\circ} \mathrm{C}$ to $250^{\circ} \mathrm{C}$ in $10 \mathrm{~min}$. Finally, the mass spectrum of each compound in the oil was compared to the standard mass spectrum in an MS library (Wiley7n.I).

\section{Oil-encapsulated niosome preparation}

Niosomes encapsulated with Plai oil were prepared by film hydration method ${ }^{22}$ with some modifications. The niosomes comprised Tween 60 and cholesterol at a 3:7 molar ratio, in which pure Plai oil was encapsulated at $0.1 \%$. After dissolving Tween and cholesterol in chloroform, the organic solvent was removed by a vacuum evaporator at $50^{\circ} \mathrm{C}-70^{\circ} \mathrm{C}$ until a thin film was obtained and kept in a desiccator for $24 \mathrm{~h}$. Then, distilled water was added to dissolve the film and to obtain niosomal suspension, which was then subjected to sonication with four cycles of $2 \mathrm{~s}$ and pause of $2 \mathrm{~s}$, using a probe sonicator (Bandeline, Berlin, Germany), followed by a 2 s pause. Finally, the oil-encapsulated niosomes were analyzed to confirm whether they fall within the accepted size range $(200-500 \mathrm{~nm})$, and their morphology was confirmed with a Zetasizer (Malvern Instruments Ltd, Malvern, UK) and transmission electron microscope (JEM-1200EX; JEOL Co., Akishima, Tokyo, 
Japan) with $\times 12.0 \mathrm{~K}$ magnification and optical microscope (HFX-DX; Nikon, Minato, Tokyo, Japan).

\section{Lipopolysaccharide (LPS)-induced subcutaneous inflammatory assay in rats}

This animal study was conducted in accordance with the guidelines for care and use of laboratory animals. This study approved by the Animal Care Committee, Faculty of Medicine, Chiang Mai University, Thailand. The study protocol was in accordance with a previous study. ${ }^{23}$ Male Wistar rats (aged 5-8 weeks, weight 250-300 g) were purchased from the National Laboratory Animal Center, Mahihol University, Bangkok, Thailand. They were housed in individual cages and maintained at an ambient temperature of $24^{\circ} \mathrm{C} \pm 1^{\circ} \mathrm{C}$ at the Faculty of Medicine, Chiang Mai University, Thailand. All the rats were selected and placed into five cages by sampling method and fasted for $16 \mathrm{~h}$ before the experiment. The experimental animals were divided into five groups: group 1 was injected with normal saline solution (control; $\mathrm{n}=5$ ) and groups $2-5$ were injected with LPS from Porphyromonas gingivalis at a concentration of $0.1 \mathrm{mg} / 0.1 \mathrm{~mL}$ per area, gently in the subcutaneous area. At $48 \mathrm{~h}$ or day 2 postinjection, the rats in group 2 were not treated, those in group 3 were treated with ultrasound via non-oil-encapsulated niosomes gel, those in group 4 were treated with oil-encapsulated niosomes gel, and those in group 5 were treated with ultrasound via neurofen gel.

\section{Ultrasound program}

Ultrasound (Intelect ${ }^{\circledR}$; Chattanooga Medical Supply, Inc, TN, USA) was used in accordance to the treatment guideline, ${ }^{24}$ with head sound sizes of $2 \mathrm{~cm}^{2}, 0.2 \mathrm{w} / \mathrm{cm}^{2}$ and $3 \mathrm{MHz}$ for $3 \mathrm{~min}$, with circulating direction technique on the inflamed area
(Figure 1A). Nearly $400 \mathrm{mg}$ of gel was used for treatment on head sound in groups 3-5. All treatment was repeated daily for 3 days. The skin temperature $\left({ }^{\circ} \mathrm{C}\right)$ and blood flow (flux per min) were detected with an optical probe and the inflamed skin area was treated directly each day by a laser Doppler blood flow meter (TDR4; MOOR Instrument, Axminster, UK) (Figure 1B).

\section{Statistical analysis}

The results were expressed as mean and standard error of mean. Repeated measurement one-way ANOVA in SPSS version 16.0 (SPSS Inc., Chicago, IL, USA) was used to compare between groups statistically on each day, and the significant level was $P<0.01$.

\section{Results}

Results of DPPH radical inhibitory activity by standard Trolox showed a liner correlation $\left(R^{2}=0.989\right)$ between concentration and percentage inhibition (Figure 2A). Whereas the activity of Plai oil in inhibiting the DPPH radical had no linear response compared to standard Trolox, but activity increased with an increase in the doses: $12.5 \mu \mathrm{g} / \mathrm{mL}(2.5 \% \pm 1.1 \%)$, $25 \mu \mathrm{g} / \mathrm{mL}(7.5 \% \pm 1.4 \%), 50 \mu \mathrm{g} / \mathrm{mL}(12.3 \% \pm 1.3 \%)$, $100 \mu \mathrm{g} / \mathrm{mL}(21.2 \% \pm 1.8 \%), 150 \mu \mathrm{g} / \mathrm{mL}(26.6 \% \pm 1.6 \%)$, $200 \mu \mathrm{g} / \mathrm{mL}(32.2 \% \pm 2.1 \%)$, and $400 \mu \mathrm{g} / \mathrm{mL}(51.3 \% \pm 1.3 \%)$ (Figure 2B). GC-MS analysis found four main active compounds: terpenen-4-ol (48\%), sabinene (19\%), DMPBD $(15 \%)$, and $\gamma$-terpinene $(2.8 \%)$ (Figure 3$)$.

The maximum load of Plai oil in niosomes was $0.1 \%$, which is the best concentration for physical stability compared to higher concentrations of $0.5 \%, 1.0 \%, 1.5 \%$, and $2.0 \%$, in room temperature without particle precipitation. Figure 4 shows the characteristics of niosomes encapsulated with and
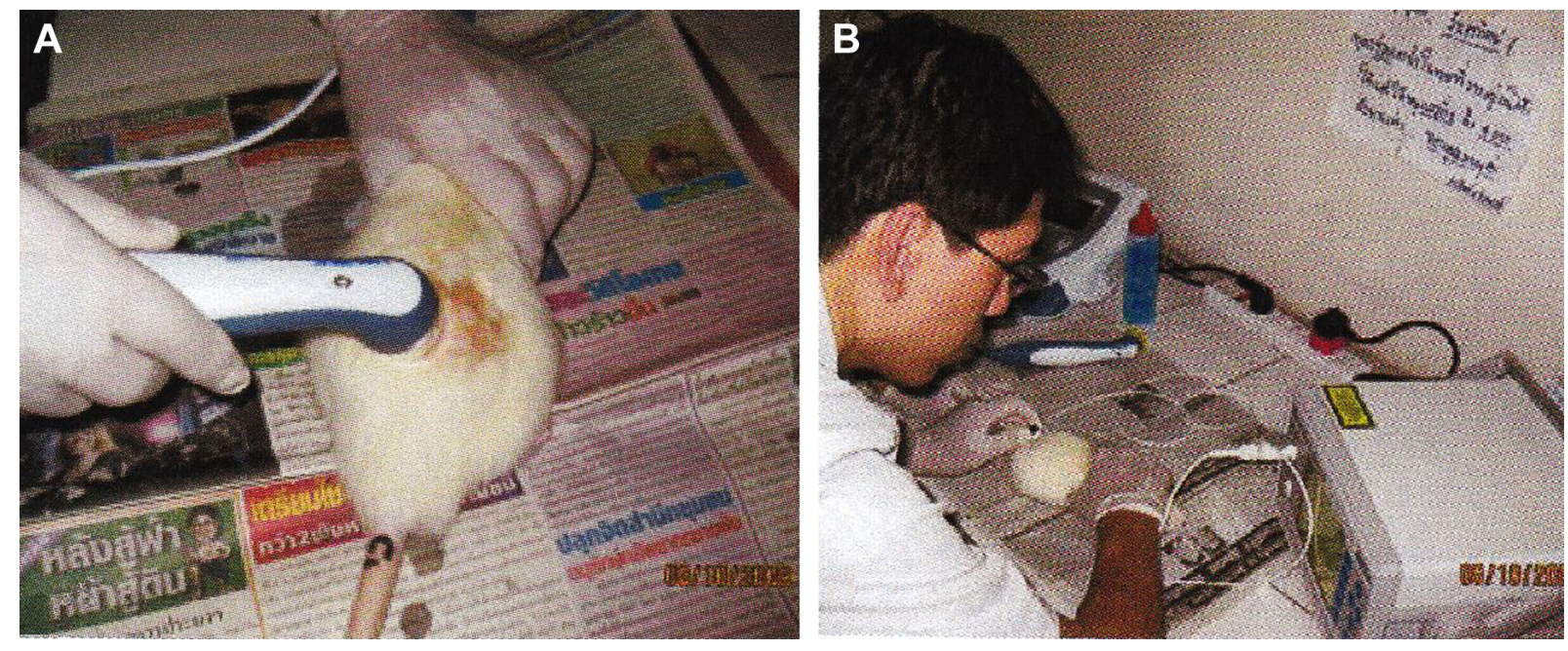

Figure I Ultrasound therapy on local subcutaneous inflammation in rat (A), and skin temperature and blood flow determined by TDR4 instrument (B). 

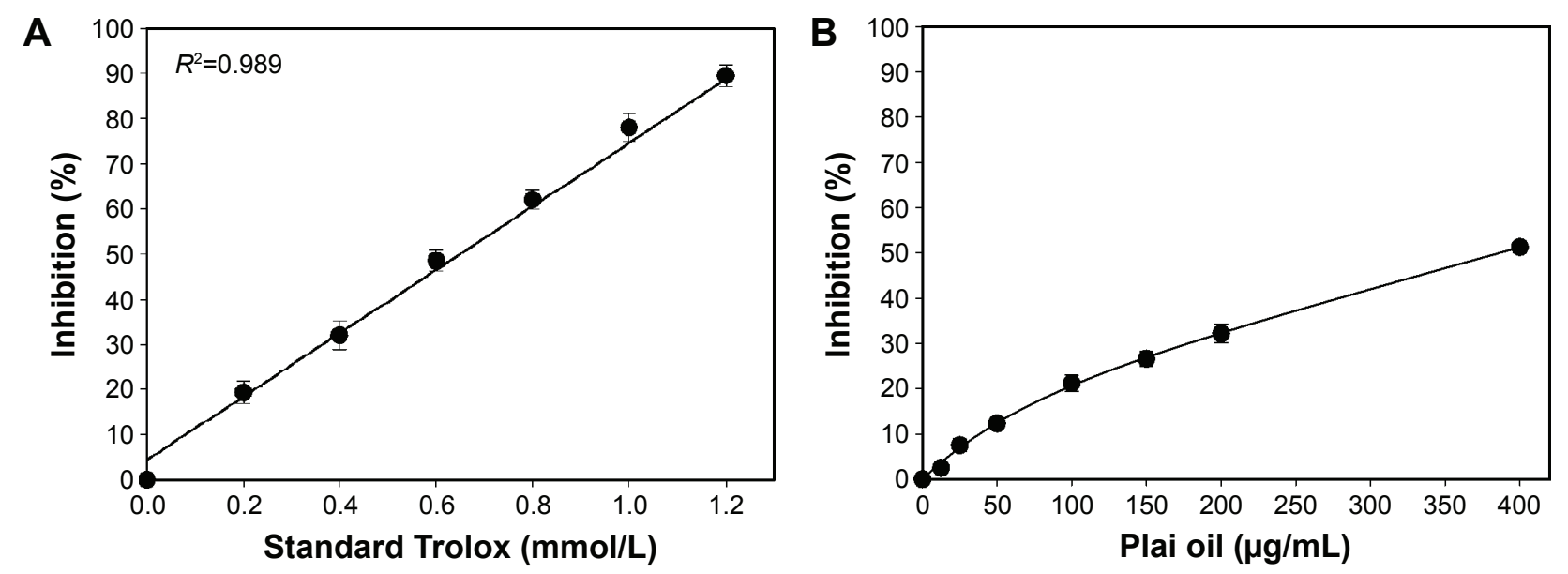

Figure 2 The percentage inhibition of DPPH radicals between standard Trolox $(0.2-1.2 \mathrm{mmol} / \mathrm{L})(\mathbf{A})$ and Plai oil $(12.5-400 \mu g / \mathrm{mL})(\mathbf{B})$. Abbreviation: DPPH, 2,2-diphenyl-I-picrylhydrazyl.

without Plai oil. The particle size of niosomes was evaluated by transmission electron microscopy at $20,000 \times$ and compared with a $100 \mathrm{~nm}$ scale (Figure 4A and B). The particle size also was observed by an optical microscope at $1,000 \times$ and compared with the microscope scale (nm) (Figure 4C). After preliminary niosomes preparation with various conditions, Tween 60 and cholesterol at 3:7 molar ratio at a final solution of $1.0 \%(\mathrm{w} / \mathrm{v})$, Plai oil-encapsulated niosomes was suitably applied in therapeutic ultrasound in this study (Figure 5).

The results show that the skin temperature and blood flow increased significantly after LPS injection on days 1 and 2 (Table 1 and Figure 6) compared to the non-LPS-injected group and control rats $(P<0.01)$. Application of therapeutic ultrasound, with gel-based control, gel-based nerofen, and gel-based nioplai (Figure 1), showed significantly lower skin

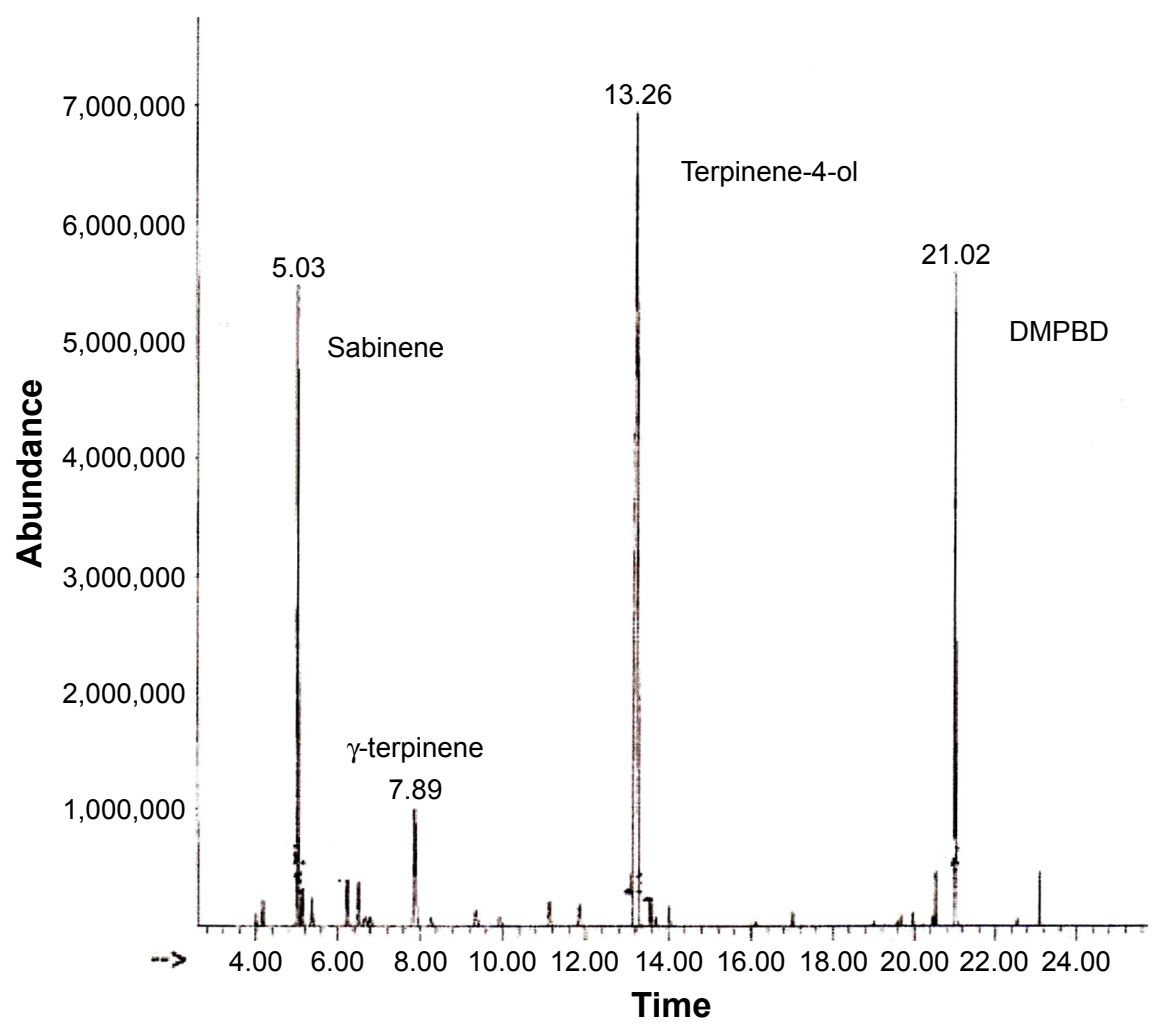

Figure 3 Peaks of four active compounds sabinene, $\gamma$-terpinene, terpinene-4-ol, and DMPBD obtained by GS-MS analysis. Abbreviations: DMPBD, E-I-(3,4-dimethoxyphenl) butadiene; GS-MS, gas chromatography-mass spectrophotometry. 

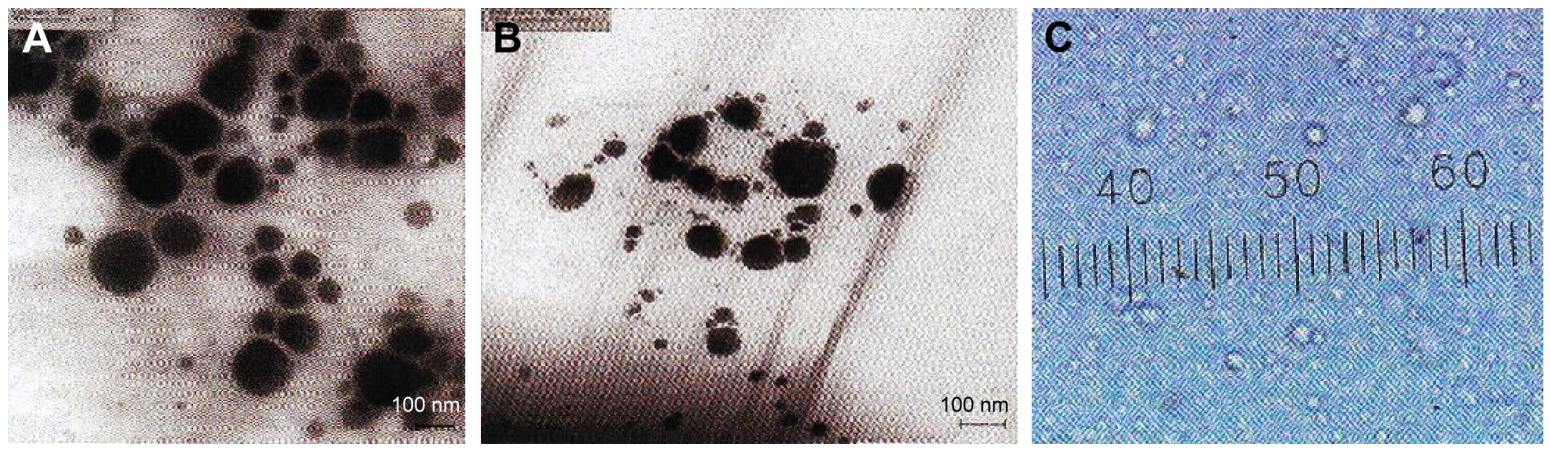

Figure 4 Characteristics of niosomes with entrapped pure Plai oil (A) observed under transmission electron microscope at 20,000×, compared to niosomes without entrapped Plai oil (B). Niosomes with encapsulated pure Plai oil (C) observed under optical microscope at I,000×.

temperatures and blood flow after treatment on days 2-4 (Figure $6 ; P<0.01$ ) compared to the LPS group. Groups that received ultrasound with gel-based nioplai showed lower skin temperature and blood flow compared to those that received gel-based nerofen.

\section{Discussion}

This was a preliminary study that analyzed the antiinflammatory, ${ }^{9}$ anti-histamine, ${ }^{10}$ and anti-pain activities of natural oil from Plai (Z. cassumunar Roxb.). ${ }^{12}$ Moreover, this study evaluated the antioxidant activity of Plai oil by scavenging DPPH radicals. Although methods such as ferric reducing antioxidant power (FRAP) and DPPH protocols have been documented in previous study for evaluating the antioxidant activity of essential oil, DPPH method responded greatly to the antioxidant activity of essential oil. ${ }^{25}$ DPPH results of this study confirmed the antioxidant activity of Plai oil. But the concentrations of each compound compared to previous studies were different: sabinene $(25 \%-45 \%)$, $\gamma$-terpinene $(5 \%-10 \%)$, $\alpha$-terpinene $(2 \%-5 \%)$, terpinene-4-ol $(25 \%-45 \%)$, and DMPBD (1\%-10\%), ${ }^{13}$ sabinene $(27 \%-34 \%), \gamma$-terpinene $(6 \%-8 \%), \alpha$-terpinene (4\%-5\%), terpinene-4-ol (30\%-35\%), and DMPBD $(12 \%-19 \%) .{ }^{26}$ In addition, a 2016 study found that Plai rhizome contains terpinene-4-ol $(40.5 \% \pm 6.6 \%)$ and sabinene $(17.4 \% \pm 1.4 \%)^{18}$ as active compounds. However, this study identified four active compounds: terpenen-4-ol (48\%), sabinene (19\%), DMPBD (15\%), and $\gamma$-terpinene $(2.8 \%)$ by GC-MS. Different results may be possible due to age, growing area, and material preparation before oil extraction.

Plai oil-encapsulated niosomes were prepared following a well-known pharmaceutical protocol. Niosomes are nonionic surfactant-based vesicles, similar to liposomes that are able to encapsulate either hydrophilic or lipophilic compounds, but with lower cost and greater stability. ${ }^{27}$ Moreover, protection of active compounds in Plai oil can be improved when encapsulated in niosomal membrane composed of Tween 60 and cholesterol. In addition, the results of this study are in agreement with that of a 2016 study, which shows that essential oil-encapsulated microemulsions, composed of Tween
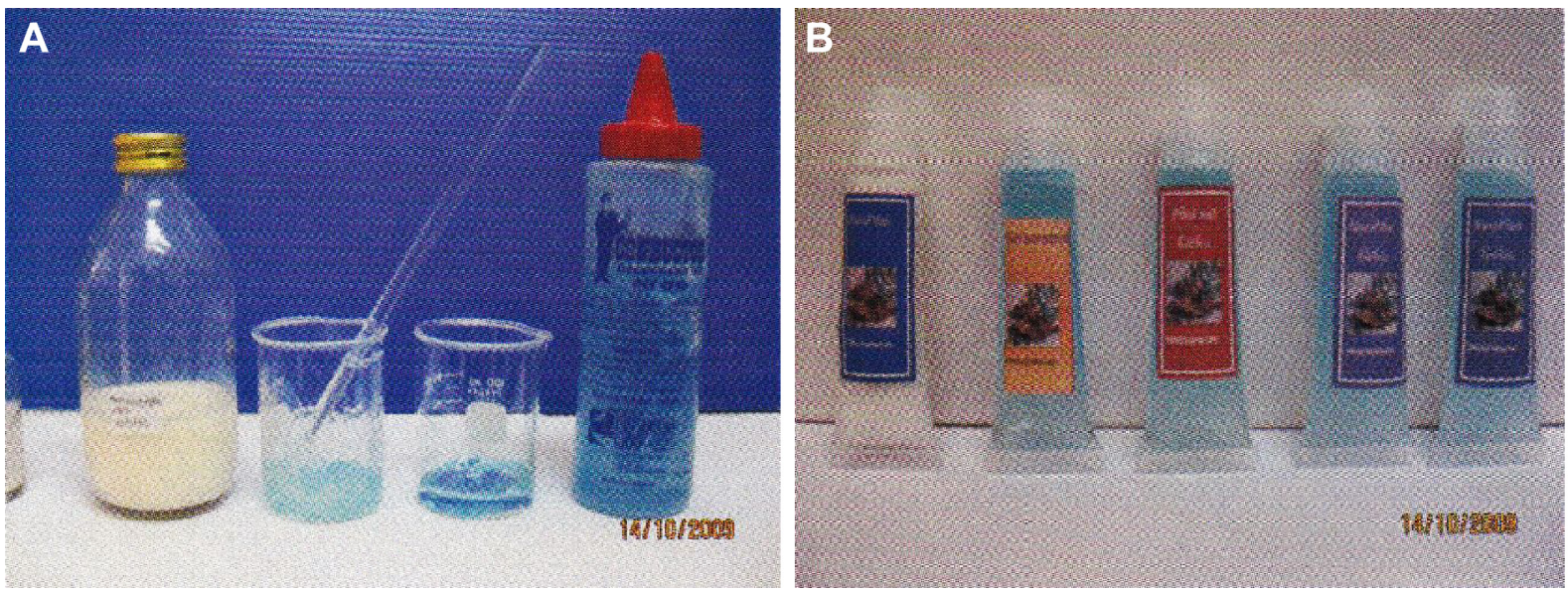

Figure 5 Oil-encapsulated niosomes and gel-based control (A) and pilot gels containing oil-entrapped niosomes (B). 
Table I Skin temperature and blood flow between groups in 4 days compared to before (day 0 ) experiment

\begin{tabular}{|c|c|c|c|c|c|}
\hline & $\begin{array}{l}\text { Control } \\
(n=5)\end{array}$ & $\begin{array}{l}\text { LPS } \\
(n=5)\end{array}$ & $\begin{array}{l}\text { LPS }+ \\
\text { based gel } \\
(n=5)\end{array}$ & $\begin{array}{l}\text { LPS }+ \\
\text { nioplai/gel } \\
(n=5)\end{array}$ & $\begin{array}{l}\text { LPS }+ \\
\text { neurofen } \\
(n=5)\end{array}$ \\
\hline \multicolumn{6}{|c|}{ Skin temperature $\left({ }^{\circ} \mathrm{C}\right)$} \\
\hline \multicolumn{6}{|c|}{ Days } \\
\hline 0 & $28.9 \pm 1.1$ & $29.1 \pm 1.1$ & $29.3 \pm 0.9$ & $28.9 \pm 1.1$ & $29.2 \pm 1.1$ \\
\hline 1 & $29.1 \pm 1.3$ & $32.2 \pm 1.1$ & $31.3 \pm 1.1$ & $31.2 \pm 1.2$ & $31.1 \pm 1.2$ \\
\hline 2 & $28.7 \pm I .1$ & $35.2 \pm 1.2$ & $34.1 \pm 1.2$ & $32.2 \pm 1.2$ & $33.1 \pm 1.3$ \\
\hline 3 & $28.9 \pm 0.9$ & $34.2 \pm 1.3$ & $32.7 \pm 1.4$ & $30.1 \pm 1.1$ & $31.8 \pm 1.4$ \\
\hline 4 & $28.7 \pm 1.2$ & $33.1 \pm 1.2$ & $31.9 \pm 1.3$ & $29.4 \pm 1.2$ & $31.1 \pm 1.3$ \\
\hline \multicolumn{6}{|c|}{ Blood flow (flux/min) } \\
\hline 0 & $65.5 \pm 1.2$ & $66.5 \pm 2.2$ & $64.5 \pm 0.9$ & $63.4 \pm 1.1$ & $66.5 \pm 1.1$ \\
\hline 1 & $67.7 \pm 1.3$ & $76.9 \pm 1.6$ & $78.3 \pm 1.1$ & $75.4 \pm 1.2$ & $77.23 \pm 1.2$ \\
\hline 2 & $64.2 \pm 1.1$ & $132.5 \pm 2.3$ & $129.1 \pm 1.2$ & $92.3 \pm 1.3$ & $110.0 \pm 1.3$ \\
\hline 3 & $67.2 \pm 0.9$ & $129.0 \pm 2.18$ & $\mathrm{II} 5.0 \pm \mathrm{I} .4$ & $85.3 \pm 1.1$ & $100.0 \pm 1.4$ \\
\hline 4 & $68.3 \pm 1.2$ & $128.2 \pm 3.5$ & $109.5 \pm 1.3$ & $76.2 \pm 1.2$ & $94.2 \pm 1.3$ \\
\hline
\end{tabular}

Note: The mean and standard error of mean are from five rats in each group. Abbreviation: LPS, lipopolysaccharide.

20 and propylene glycol (2:1) in water, could stabilize active compounds such as sabinene. In addition, previous reports also have claimed that niosomes are able to promote any compound passing through the skin. ${ }^{28}$ Transmission electron microscope and optical microscope analysis indicated that niosomes fall within a range of $100 \mathrm{~nm}$. However, niosome permeability theory proposes that not only small-sized particles penetrate through the skin, ${ }^{29}$ but also an optimum ratio of lipid or surfactant may increase the flexibility of the bilayer membrane..$^{30}$ On the other hand, both liposomes and niosomes revealed significant permeability and nontoxicity on mammalian skin. ${ }^{14-16}$ Thus, application of niosomes to eliminate subcutaneous inflammation is possibly safe.

Application of therapeutic ultrasound in combination with physical therapy was summarized in an application and safety considerations report, ${ }^{31}$ which proposes that ultrasound can assist in transporting compound, especially a drug, into the skin via a phonophoresis technique or sonophoresis method. ${ }^{1}$ Moreover, the ultrasound program with $0.2 \mathrm{~W} / \mathrm{cm}^{2}, 3 \mathrm{MHz}$ for $3 \mathrm{~min}$ and circulating technique around the inflamed area was designed following the universal anti-inflamed program in the physical therapy clinic. ${ }^{24}$ Similar evidence on skin healing discussed in previous reports shows the preferred intensity to be $0.2 \mathrm{~W} / \mathrm{cm}^{2}$ when a $1-3 \mathrm{MHz}$ machine is used. ${ }^{32}$ A previous report suggested that drug delivered can pass the transdermal stratum corneum $(10-30 \mu \mathrm{m})$ and form a barrier that stops passive drug diffusion by applying low-frequency ultrasound $(<100 \mathrm{kHz}) .^{33}$ In addition, a recent study proposed that the cavitation mechanism of ultrasound is possible for drug delivery by sonophoresis, ${ }^{34}$ which relates to a previous report on drug absorption in capillary vessels after crossing the stratum corneum. ${ }^{35}$ Furthermore, the ultrasound program in this study followed the universal anti-inflamed program in the clinic.

An animal study that focused on subcutaneous inflammation in accordance to a previous study ${ }^{23}$ showed that subcutaneous injection of $100 \mu \mathrm{L}$ of LPS at $0.1 \mathrm{mg}$ to generate an inflammatory condition resulted in an inflamed knob after $24-48 \mathrm{~h}$ of postinjection. LPS induces inflammation and involves specific intracellular events of transduction; for example, protein kinase $\mathrm{C}$, tyrosine kinase, and
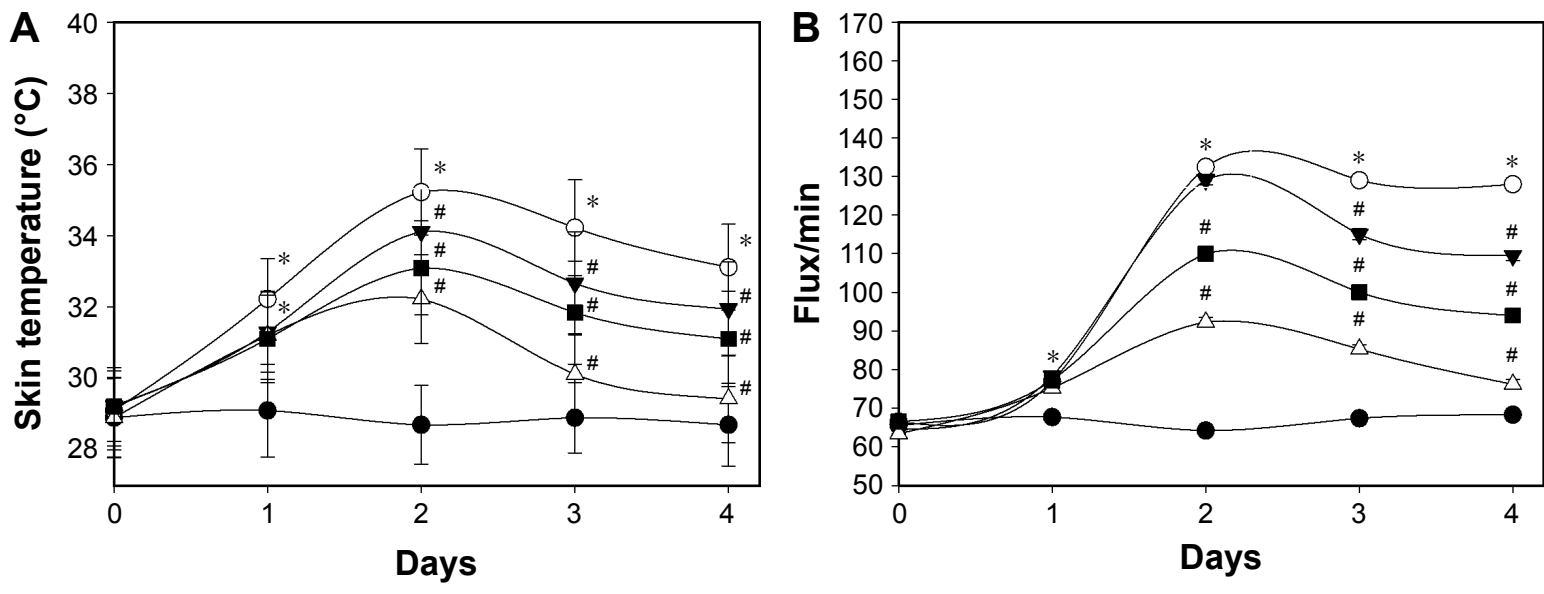

- Control $-\mathrm{O}$ - LPS $\rightarrow$ LPS + niosome (placebo) $\rightarrow-$ LPS + nioplai

LPS + neurofen

Figure 6 Skin temperature $\left({ }^{\circ} \mathrm{C}\right)(\mathbf{A})$ and blood flow (flux) (B) between the five groups at before (day 0 ) and during 4 days experiment without or with LPS injection via therapeutic ultrasound treatment with niosome placebo, nioplai or neurofen. Each point presents the mean and standard error of mean from each of five rats. $* P<0.01$ compared to the control group on each day, and ${ }^{\#} P<0.01$ when compared to the LPS group on each day.

Abbreviation: LPS, lipopolysaccharide. 
mitogen-activated protein kinase. ${ }^{36}$ During the inflammation period, signs such as local edema, high temperature, and redness are presented, ${ }^{37}$ as well as increase in skin blood flow due to microvascular remodeling and release of histamine responses. ${ }^{38}$ Thus, highest skin temperatures and blood flow were presented by the LPS-treated rat groups, whereas no responses occurred in the non-LPS-injected group.

Group that received ultrasound with niosome placebo on days 2-4 showed decreased skin temperature and blood flow, but those that received ultrasound treatment with Plaioil entrapped niosomes showed significantly lower skin temperature and blood flow compared to those that received ultrasound, placebo, and neurofen drug $(P<0.01)$. Neurofen is a positive anti-inflammatory drug that is used as a standard comparison to Plai oil. It contains ibuprofen that has been reported as a nonsteroidal anti-inflammatory drug and works by acting on a group of compounds called prostaglandins. It also acts as a non-selective inhibitor of cyclooxygenase-1 (COX)-1 and $-2 .{ }^{39}$ Neurofen containing ibuprofen together with ultrasound treatment presents anti-inflammation by reducing skin temperature and blood flow, but it has less activity than that of Plai oil-encapsulated niosomes. Possible mechanisms on some ingredients or active compounds in neurofen involve skin permeability, and this is still unclear. This study could not confirm the concentration of Plai oil in the inflamed subcutaneous area, but positive results may reflect some benefits of Plai oil in the niosome that can pass through the skin from ultrasound application. Moreover, compounds of Plai oil that act on the prostaglandin pathway are different from neurofen. Plai oil contains more active compounds and has various functions, for example, $\mathrm{DMPBD}^{40}$ and phenylbutenoids inhibit COX-2 activity. ${ }^{41}$ Furthermore, a study by Chaiyana et al also reported that sabinene and terpinene-4-ol could reduce the expression of nuclear factor-kappa and interleukin-6 released in human peripheral blood mononuclear cells, which reflected the compounds' anti-inflammatory activity. ${ }^{18}$ Unfortunately, this study did not evaluate the effect of application of neurofen and Plai oil on anti-inflammatory pathways, which may be studied more in the future.

\section{Conclusion and limitations}

This preliminary study showed the possibility of applying a natural medicinal plant product, such as Plai oil with active compounds in a niosomal system, for inhibiting inflammation via therapeutic ultrasound. However, this study could not confirm skin permeability, active compound distribution, or pharmacokinetics in human skin, and more research are needed to confirm these results.

\section{Acknowledgments}

This study received a grant from the Thailand Research Fund (TRF) (MRG5080140). We thank a corresponding author, Jirakrit Leelarungrayub, for providing consent to publish Figure 1B.

\section{Author contributions}

JL was responsible for obtaining funding, experimental design, establishing all protocols, and performing all testing and data analysis. JM and AM prepared and established the preparation of niosomes and also assisted in rechecking the original and final versions of the manuscript. All authors contributed toward data analysis, drafting and revising the paper and agree to be accountable for all aspects of the work.

\section{Disclosure}

The authors report no conflicts of interest in this work.

\section{References}

1. Machet L, Boucaud A. Phonophoresis; efficiency, mechanisms and skin tolerance. In J Pharm. 2002;243(1-2):1-15.

2. Robertson VJ, Baker KG. A review of therapeutic ultrasound; effectiveness studies. Phys Ther. 2001;81(7):1339-1350.

3. Silberstein J, Lakin CM, Kellogg Parsons J. Shock wave lithotripsy and renal hemorrhage. Rev Urol. 2008;10(3):236-241.

4. Elisha IL, Dzoyem JP, McGaw LJ, Botha FS, Eloff JN. The antiarthritic, anti-inflammatory, antioxidant activity and relationships with total phenolics and total flavonoids of nice South African plants used traditionally to treat arthritis. BMC Complement Altern Med. 2016;16:307.

5. de Brum TF, Camponogara C, da Silva Jesus R, et al. Ethnopharmacological study and topical anti-inflammatory activity of crude extract from Poikilacanthus glandulosus (Nees) Ariza leaves. J Ethnopharmacol. 2016;193:60-67.

6. Ndoye Foe FM, Tchinang TF, Nyegue AM, et al. Chemical composition, in vitro antioxidant and anti-inflammatory properties of essential oils of four dietary and medicinal plants from Cameroon. BMC Complement Altern Med. 2016;16:117.

7. Ruangnoo S, Jaiaree N, Makchuchit S, Panthong S, Thongdeeying P, Itharat A. An in vitro inhibitory effect on raw 264.7 cells by antiinflammatory compounds from Smilax corbularia Kunth. Asian Pac J Allergy Immunol. 2012;30(4):268-274.

8. Kakatum N, Jaiarree N, Makchucit S, Itharat A. Antioxidant and antiinflammatory activities of Thai medicinal plants in Sahasthara remedy for muscle pain treatment. J Med Assoc Thai. 2012;95(Suppl 1): S120-S126.

9. Wasuwat S, Nandhasri P, Suntorntanasat T, Rojjanapothi W. Antiinflammatory action of Plai oil, Zingiber cassumunar Roxb. Presented at: The First Princess Chulabhorn Science Congress; December 10-13; 1987; Bangkok, Thailand.

10. Piromrat K, Tuchinda M, Geadsomnuig S, Koysooko R, Bunjob M. Antihistamic effect of Plai (Zingiber cassumunar Roxb.) on histamine skin test in asthmatic children. Siriraj Hosp Gaz. 1986;38(4):251-256.

11. Anantasan V, Asayakun S. Study on the local anesthetic effect of squeenzed Zingeber cassumuna Robx. Chiangmai Med Bull. 1971;10(1): $10-23$.

12. Panthong A, Kanjanapothi D, Niwatananun V, Tuntiwachwuttikul P, Reutrakul V. Anti-inflammatory activity of compounds isolated from Zingiber cassumnar. Planta Med. 1990;56(6):655. 
13. Masuda T, Jitoe A. Antioxidative and anti-inflammatory compounds from tropical gingers; Isolation, structure determination, and activities of cassumunins A, B, and C, new complex curcuminoids from Zingiber cassumunar. J Agr Food Chem. 1994;42(9):1850-1856.

14. Kiatyingunsulee N, Wangmad M, Swasdimongkul D, Mokkhasmit M. Some pharmacological studies of active constitute in Plai (Zingiber cassumunar Roxb.) Bull Dep Med Sci (Thailand). 1979;21:13-24.

15. Panyathanya R, Gnamwat W, Chawalidthumrong P, Permpipat U, Lellakulthanit O, Chantachaya C. Study of acute and chronic toxicity of Plai (Zingiber cassumunar Roxb.) in rats. Siriraj Hosp Gaz. 1986;38(6):413-416.

16. Mokkhasmit M, Swatdimongkol K, Satrawaha P. Study on toxicity of Thai medicinal plants. Bull Dept Med Sci. 1971;12(2/4):36-65.

17. Pongsakorn S, Koysooko R, Pinthong T, Morasakul B. Pharmacokinetic studies of compound D isolated from Plai (Zingiber cassumunar Roxb.) in rat. Vajira Med J. 1988;32:101.

18. Sivakumar M, Tachibana K, Pandit AB, et al. Transdermal drug delivery using ultrasound-theory, understanding and critical analysis. Cell Mol Biol (Noisy-le-grand). 2006;51:OL767-OL784.

19. Ita K. Recent progress in transdermal sonophoresis. Pharm Dev Technol. 2015;25:1-9.

20. Ruckmani K, Sankar V, Sivakumar M. Tissue distribution, pharmacokinetics and stability studies of zidovudine delivered by niosomes and proniosomes. J Biomed Nanotechnol. 2010;6(1):43-51.

21. Thitilertdecha N, Teerawutgulraq A, Kilburn JD, Rakariyatham N. Identification of major phenolic compounds from Nephelium lappaceum L. and their antioxidant activities. Molecules. 2010;15(3):1453-1465.

22. Baillie AJ, Florence AT, Hume LR, Muirhead GT, Rogerson A. The preparation and properties of niosomes - non-ionic surfactant vesicles. J Pharm Pharmacol. 1985;37(12):863-868.

23. Shapira L, Soskolne WA, Houri Y, Barak V, Halabi A, Stabholz A. Protection against endotoxic shock and lipopolysaccharide-induced local inflammatory by tetracycline: correlation with inhibition of cytokine secretion. Infect Immun. 1996;64(3):825-828.

24. de Brito Vieira WH, Aguiar KA, da Silva KM, Canela PM, da Silva FS, Abreu BJ. Overview of ultrasound usage trends in orthopedic and sports physiotherapy. Crit Ultrasound J. 2012;4(1):11.

25. Belabbes R, Dib ME, Djabou N, et al. Chemical variability, antioxidant and antifungal activities of essential oils and hydrosol extract of Calendula arvensis L. from western Algeria. Chem Biodivers. Epub 2017 Jan 21.

26. Pongprayoon U, Tuchinda P, Claeson P, Sematong T, Reutrakul V, Soontornsaratune P. Topical antiinflammatory activity of the major lipophilic constituents of the rhizome of Zingiber cassumunar Roxb. Part II: Hexane extractives. Phytomedicine. 1997;3(4):323-326.
27. Rajera R, Nagpal K, Singh SK, Mishra DN. Niosomes: a controlled and novel drug delivery system. Biol Pharm Bull. 2011;34(7):945-953.

28. Fang JY, Hong CT, Chiu WT, Wang YY. Effect of liposomes and niosomes on skin permeation of enoxacin. Int J Pharm. 2001;219(1-2): 61-72.

29. Ceve G, Schätzlein A, Blume G. Transdermal drug carrier; basic properties, optimization and transfer efficiency in the case of epicutaneouslyapplied peptide. J Control Release. 1995;36(1-2):3-16.

30. Hofer C, Hartung R, Göbel R, Deering P, Lehmer A, Breul J. New ultradeformable carrier for potential transdermal application of interleukin-2 and interferon- $\alpha$ : theoretic and practical aspects. World J Surg. 2000;24(10):1187-1189.

31. Miller DL, Smith NB, Balley MR, et al. Overview of therapeutic ultrasound applications and safety considerations. JUltrasound Med. 2012; 31(4):623-634.

32. Dyson M, Franks C, Suckling J. Stimulation of healing of varicose ulcers by ultrasound. Ultrasonics. 1976;14(5):232-236.

33. Pitt WG, Husseini GA, Staples BJ. Ultrasonic drug delivery - a general review. Expert Opin Drug Deliv. 2004;1(1):37-56.

34. Park D, Park H, Seo J, Lee S. Sonophoresis in transdermal drug deliverys. Ultrasonics. 2014;54(1):56-65.

35. Mitragotri S, Kost J. Low-frequency sonophoresis: a review. Adv Drug Deliv Rev. 2004;56(5):589-601.

36. Dong Z, Qi X, Fidler IJ. Tyrosine phosphorylation of mitogen-activated protein kinase is necessary for activation of murine macrophages by natural and synthetic bacterial products. J Exp Med. 1993;177: 1071-1077.

37. Taylor PM, Robertson SA, Dixon MJ. Evaluation of the use of thermal thresholds to investigate NSAID analgesia in a model of inflammatory pain in cats. J Feline Med Surg. 2007;9:313-318.

38. Huggenberger R, Detmar M. The cutaneous vascular system in chronic skin inflammation. J Investig Dermatol Symp Proc. 2011;15(1): 24-32.

39. Bushra R, Aslam N. An overview of clinical pharmacology of ibuprofen. Oman Med J. 2010;25(3):155-1661.

40. Jeenapongsa R, Yoovathaworn K, Sriwatanakul KM, Pongprayoon U, Sriwatanakul K. Anti-inflammatory activity of (E)-1-(3,4-dimethoxyphenyl) butadiene from Zingiber cassumunar Roxb. J Ethnopharmacol. 2003;87(2-3):143-148.

41. Han AR, Kim MS, JeongYH, Lee SK, Seo EK. Cyclooxygenase-2 inhibitory phenylbutenoids from the rhizomes of Zingiber cassumunar. Chem Pharm Bull (Tokyo). 2005;53(11):1466-1468.
International Journal of Nanomedicine

\section{Publish your work in this journal}

The International Journal of Nanomedicine is an international, peerreviewed journal focusing on the application of nanotechnology in diagnostics, therapeutics, and drug delivery systems throughout the biomedical field. This journal is indexed on PubMed Central, MedLine, CAS, SciSearch ${ }^{\circledR}$, Current Contents ${ }^{\circledR} /$ Clinical Medicine,

\section{Dovepress}

Journal Citation Reports/Science Edition, EMBase, Scopus and the Elsevier Bibliographic databases. The manuscript management system is completely online and includes a very quick and fair peer-review system, which is all easy to use. Visit http://www.dovepress.com/ testimonials.php to read real quotes from published authors. 